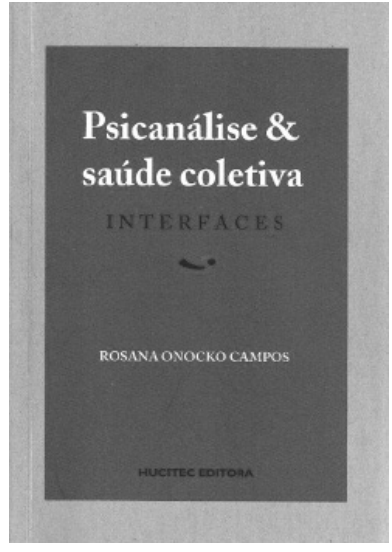

CAMPOS, R. O. Psicanálise \& Saúde Coletiva: Interfaces. São Paulo: Hucited, 2012, $172 \mathrm{p}$.
A autora é médica, formada pela Universidad Nacional de Rosario (UNR), na Argentina, pós-graduada, no Brasil, pelo Departamento de Saúde Coletiva da Faculdade de Ciências Médicas da UNICAMP, do qual tornou-se docente em 2004, e, a partir de março de 2013, professora associada (livre docente). Desde 1996, atua na formação em saúde mental e coordena o grupo de pesquisa Saúde Coletiva e Saúde Mental: Interfaces, criado em 2006.

No livro em questão, a autora aborda a articulação entre Psicanálise e Saúde Coletiva, partindo do pressuposto de que a Saúde Coletiva carece da abordagem psicanalítica na análise de várias questóes com as quais se defronta. Como afirma no prefácio, se o pensamento freudiano vem contribuindo para vários campos, como a cultura e a sociologia, entre outros, por que não para a Saúde Coletiva? O que, afinal, a Psicanálise teria a dizer à Saúde Coletiva que esta, por alguma razão, não quer ou não está conseguindo ouvir?

Articular campos tão amplos, compostos de diversas abordagens, que nem sempre conversam entre si, não é tarefa fácil. Para dar conta disso, a autora reuniu oito textos produzidos entre 2001 e 2012, alguns já publicados como artigos e outros ainda inéditos, buscando demonstrar, sob diferentes perspectivas, a relevância da introdução de conceitos da Psicanálise nos campos teórico e prático da Saúde Coletiva, com os quais, como afirma no Prefácio, encontra-se fortemente comprometida.

Apesar de terem sido produzidos em diferentes momentos e com objetivos diversos, é possível identificar nos vários textos algumas premissas básicas, que se complementam: a relevância da clínica, tantas vezes relegada a um segundo plano na Saúde Coletiva; a dificuldade ou até a impossibilidade de levar em conta a dimensão subjetiva do usuário e do profissional de saúde sem recorrer a alguns conceitos da Psicanálise; a urgência de introduzir esses conceitos, visando a complementar a formação dos profissionais de saúde; a relevância de introduzir, de forma sistemática, a supervisão clínico-institucional nas equipes de saúde, dadas as dificuldades enfrentadas no cotidiano da atenção ao cuidado, não apenas prestado ao portador de transtorno mental, mas também àquele que busca outras formas de atendimento; a necessidade de articular a Psicanálise com a análise da ideologia, para evitar cair num subjetivismo individualista e limitante; e a contextualização de tais aportes no âmbito da política de saúde brasileira, que instituiu o Sistema Único de Saúde, o SUS, cuja implementação e cujo aperfeiçoamento têm sido umas das principais "bandeiras" da Saúde Coletiva, sobretudo mediante a atuação da Associação Brasileira de Saúde Coletiva/ABRASCO, criada no final da década de 1970. 
Rosana Onocko Campos realiza essa tarefa tendo como ponto de partida a constatação de que - embora, em anos recentes, autores do campo da Saúde Coletiva reconheçam a relevância de se considerar o sujeito e não apenas as estruturas sociais - ainda há poucas referências à constituição subjetiva do sujeito. Daí, sua afirmação no Prefácio de que, na produção mais recente da Saúde Coletiva, "o sujeito pode ser histórico, social e até coletivo, mas não há referência a alguma estruturação que não seja racional. Nada de inconsciente!” (p. 12-13).

Talvez isso se deva, continua a autora, a um receio da entrada de uma 'certa'psicanálise, considerada como se fosse a única, pautada pelas práticas privatistas e lucrativas, oposta, portanto, à perspectiva da atenção à saúde no espaço público, como é o caso da Saúde Coletiva. Ao contrário, afirma a autora: "abraçamos uma psicanálise preocupada por desvendar os mecanismos pelos quais o laço fraterno seria possível, e com ele a criação e a cultura. Uma psicanálise que nos ajude a suportar um 'nós' fortemente investido e a tolerar-nos em nossas diferenças." (p. 13).

Buscar as interfaces entre Psicanálise e Saúde Coletiva exigiu um percurso teórico-metodológico de espectro bastante amplo. É o que a autora realiza, a meu ver, com grande competência, articulando contribuições de autores da Psicanálise: naturalmente, Freud, mas também Kaës e Winnicott, como o psicanalista e cientista político Cornelius Castoriadis, o marxista Althusser, os filósofos Slavoj Zizek e Paul Ricoeur, assim como Jean Oury, do campo da psicoterapia institucional, com análises de estudiosos da Saúde Coletiva, como Cecília Minayo, Jairnilson Paim, Gastão Campos, além de textos produzidos, anteriormente, por ela mesma, relacionados às áreas de gestão e planejamento e da saúde mental. Tal elaboração teórica é complementada com textos que relatam experiências de intervenções junto a equipes de saúde mental da rede básica, das quais a autora participou.

Destaco, como exemplos singulares, para comentar, dois capítulos, ambos inéditos. O capítulo dois: "Ideologia e subjetividade: a relação recalcada"; e o oitavo: "Sejamos heterogêneos: contribuições para o exercício da supervisão clínicoinstitucional em saúde mental".

Em "ideologia e subjetividade", a autora discute de que forma as concepções ideológicas vêm atuando nas propostas de políticas públicas de saúde, desde o Welfare State inglês, dos anos de 1940, até o SUS, instaurado no Brasil no final dos anos de 1980.

O caminho escolhido para apresentar e discutir o conceito de ideologia é, basicamente, o de rejeitar a teoria da ideologia como reflexo, atribuída a uma certa leitura do marxismo. Para tanto, inicia sua reflexão com Freud, a partir de obras como O Mal-estar da civilização e Mais além do princípio do prazer. Na primeira, o criador da psicanálise afirma que a civilização é fonte de sofrimento para os homens, embora seja impossível a humanidade voltar ao tempo das cavernas; na segunda, constata a enorme contradição do ser humano, durante toda a sua vida, na luta entre dois instintos/pulsões básicos: o do prazer e o da morte. Naturalmente, não de forma racional, pois, como afirma a autora, "todo sujeito é portador de algo mais 
do que o cogito cartesiano", [pois] "A descoberta do inconsciente marcou uma das grandes quebras da modernidade" (p. 42).

A partir dessa constatação inicial, a autora recorre a autores que discutiram o conceito de Ideologia com o recurso à Psicanálise. Para Castoriadis, retomando Freud, a fundação da sociedade, em sua dimensão histórico-social, só poderia se dar se ao mito da morte do pai sucedesse o pacto dos irmãos. E é a partir dessa constatação que Castoriadis elabora o conceito de "significações imaginárias", que traz contribuições para algo que a autora destaca como essencial para a sua análise: a existência das instituições mediadoras, que, ao regular as relações entre os homens e a sociedade, instituem um tipo de sujeito particular em cada sociedade, em cada contexto. Exatamente, procede de Althusser a afirmação de que, na realidade, a ideologia interroga o sujeito mediante a atuação/mediação dos aparelhos ideológicos do estado (AIE).

Se a ideologia interroga o sujeito, como pensar o SUS como política pública universal se muitos dos valores que informam e conformam a sociedade brasileira são valores individualistas e com base na meritocracia, como na sociedade norteamericana, questiona a autora?

É Zizek que, segundo a autora, encaminha a resposta a essa questão, com sua análise da ideologia em-si, quando, sob a forma de doutrina, a ideologia procura nos convencer "de sua veracidade, mas sempre servindo a algum interesse de poder", e para-si, quando a ideologia, mediante os AIEs, analisados por Althusser, ganha materialidade "nas práticas, rituais e instituiçōes". E em-si-e-para-si, quando, ao se externalizar, "a ideologia reflete sobre si mesma, produzindo a desintegração, a autolimitação e autodispersão da noção de ideologia” (p. 49-50).

Finalmente, a autora recorre a Paul Ricoeur, para quem "a ideologia é operatória e não temática, e, assim, pensaríamos 'através' dela mais do que 'sobre ela”" (p. 54). Também, para Ricoeur, haveria uma função "positiva” na ideologia, com o que está de acordo também Castoriadis, função que, segundo Rosana Onocko, “está ligada à necessidade sempre existente para um dado grupo social de conferir uma imagem de si mesmo, de representar-se" (p. 52).

Munida dessas abordagens da ideologia, a autora interpreta algumas questões de extrema relevância para o SUS, desde sua fundação até o momento, afirmando, com contundência, que "O SUS definha emparedado entre a saga dos fundadores que nunca erraram e a dos gestores que nada podem, nem sequer se demitir" (p. 54). E questiona: e daí, como intervir?

A resposta para tal indagação é o posicionamento assumido no seguinte sentido:

Por um lado, achamos que a política de saúde não pode procurar sua potência longe da clínica ou em estratégias neocolonizadoras. Tampouco a achará se desiste de produzir mudanças. Pensamos que nossas práticas deveriam se afirmar como experiência-limite entre o psíquico e o social entre o que diz respeito a uma interioridade è à formas de organização da sociedade entre a clinica e a politica. (p. 54). 
A forma de intervir, coerente com esse posicionamento, é exemplificada no capítulo oito: "Sejamos heterogêneos: contribuiçōes para o exercício da supervisão clínico-institucional em saúde mental”, iniciado pela autora com a discussão do conceito de supervisão, também originado da Psicanálise, mas que, ao ser instituída no contexto da Reforma Psiquiátrica brasileira nos serviços substitutivos do Centro de Atenção Psicossocial (CAPS), qualificou-se com o complemento clínico-institucional, com o sentido, a autora esclarece, ao se posicionar sobre as concepções de instituição, de sujeito que sofre, porque é portador de transtorno mental, e, enfim, sobre as relações entre os profissionais, os usuários e a instituição CAPS.

O conceito de instituição está apoiado em Freud e, sobretudo, em Kaës, que assinala o caráter permanente da instituição que pode, assim, assegurar estabilidade à vida psíquica e social. Reconhece, também, considerações de René Lourau, um dos fundadores da Análise Institucional francesa, para quem o CAPS poderia ser considerado como uma organização atravessada por instituições, entre as quais a autora destaca a Psiquiatria, a loucura, o conceito de reabilitação e a institucionalização da violência nos bairros, com a consequente institucionalização de uma subjetividade marcada pela marginalidade.

Ao trazer a concepção de sujeito que sofre, a autora parte do pressuposto da capacidade criativa de todo sujeito, destacando, a seguir, as diferenças quando se trata de pacientes com diagnóstico de psicose, com seu modo singular de conceber a relação espaço-tempo e de tolerar as frustrações, tendência que pode ser diminuída pela medicação psicotrópica. Destaca a contribuição de Jean Oury, quando este sugere instituir, junto ao corpo de profissionais, técnicas de mediação, denominadas objetos institucionais, como oficinas e reuniōes, nos quais se poderá instituir um novo Coletivo para indicar quais deverão ser os construtos de uma supervisão clínicoinstitucional.

Para tanto, é fundamental a noção de clínica ampliada, no sentido atribuído por Gastão Campos, "entrelaçando clínica e política, tratamento, organização institucional, gestão e subjetividade” (p. 156).

A seguir, Rosana Onocko Campos ressalta que a montagem do dispositivo de supervisão clínico-institucional, no tocante à relação entre agentes e instituição, deve levar em conta a possibilidade de os trabalhadores construírem uma certa grupalidade entre eles, de se distanciarem um pouco da sua prática a fim de poderem melhor pensar sobre ela, o que a autora chama de "uma pausa, um breque, uma vírgula". E, enfim, que o supervisor ofereça um suporte, apoiando a articulação de novos conceitos e teorizaçôes, a fim de que os agentes de trabalho possam construir novas categorias de análise.

Afirma, ainda, que "tomamos a supervisão clínico-institucional como um dispositivo de formação e intervenção" (p. 164), e assinala suas principais estratégias, que são: a análise permanente da organização do processo de trabalho e do cotidiano e a discussão e construção coletiva dos casos, pois, em última análise, é a discussão do caso que deve orientar a organização da prática da instituição, e tal operação só se pode dar em equipe. (p. 169). 
Finalizando, a autora recorre às noções de suporte (holding) e manejo (handing), ambas de Winnicott, que devem ser exercidas pelo supervisor clínico-institucional: suporte no sentido de "suportar os outros no seu processo de constituição como grupo subjetivo, sabendo o que está em jogo: identificação, narcisismo, angústia de dissolução, pacto denegatório etc. e manejo de se saber o que fazer, ter alguma coisa para ofertar, caminhos para mostrar. Alguns conceitos com relação à clínica das psicoses, às formas de operar o Coletivo, certa forma de organizar a participação no serviço etc.” (p. 171).

Por tudo isso, entendo como fundamental e da maior relevância a contribuição da Professora Rosana Onocko Campos para a Saúde Mental, no âmbito da Saúde Coletiva. De forma crítica e ética, mas apontando saídas e formas já "testadas" de trabalhar e intervir junto às equipes da rede substitutiva dos CAPSs, a autora demonstra que a articulação entre Psicanálise e Saúde Coletiva não é apenas possível, mas absolutamente necessária. E quero crer também que, depois de ler e refletir sobre os questionamentos feitos pela autora nesse belo livro, e de forma tão corajosa, será impossível aos trabalhadores, estudiosos e militantes da Saúde Mental, no contexto do SUS, ignorarem as contribuições da Psicanálise para a Saúde Coletiva. Meu desejo final é que a Saúde Coletiva vá adquirindo a capacidade de ouvir o que a Psicanálise tem a lhe dizer, o que, como demonstra a autora, não é pouca coisa!

\section{Solange L'Abbate}

\footnotetext{
${ }^{1}$ Livre-docente pela Universidade Estadual de Campinas (UNICAMP) - Campinas (SP), Brasil. Professora associada do departamento de Saúde Coletiva da Faculdade de Ciências Médicas da UNICAMP - Campinas (SP), Brasil. 